\title{
Factors associated with neonatal death among adolescent mothers
}

Viviane Maria Gomes de Araujo 1

iD https://orcid.org/0000-0002-9195-4074

Juliana Santana da Silva 2

(iD) https://orcid.org/0000-0002-2824-1290

Carolina Luiza Bezerra Silva 3

(iD https://orcid.org/0000-0002-9080-4285

Maria do Socorro de Oliveira Costa 4

iD https://orcid.org/0000-0003-3699-9381

Emília Chagas Costa 5

(iD) https://orcid.org/0000-0002-7664-5994

\author{
Paulo Germano Frias 6 \\ iD https://orcid.org/0000-0003-4497-8898 \\ Mauro Virgílio Gomes de Barros 7 \\ (iD https://orcid.org/0000-0003-3165-0965 \\ Marco Aurélio de Valois Correia Junior 8 \\ (iD https://orcid.org/0000-0003-0386-5256
}

1,7,8 Programa de Pós-graduação em Hebiatria. Universidade de Pernambuco. Av. Agamenon Magalhães, 141. Recife, PE, Brasil. CEP: 50.100-010. E-mail: marcovalois@gmail.com

2 Universidade de Pernambuco. Recife, PE, Brasil.

3,4,6 Instituto de Medicina Integral Prof. Fernando Figueira. Recife, PE, Brasil.

5 Programa de Pós-graduação em Nutrição. Universidade Federal de Pernambuco. Recife, PE, Brasil.

\begin{abstract}
Objectives: to analyze factors associated with neonatal death among adolescent mothers.

Methods: randomized hospital-based cross-sectional study in a tertiary institution, , data from the Sistema de Informação sobre Nascidos Vivos (Sinasc), (Live Birth Information System), Sistema de Informação sobre Mortalidade (SIM) (Mortality Information System), and medical records. The study population was comprised of 1,341 adolescents aged 10-19 who had assisted childbirth at the institution between 2012 to 2016. The independent variables were sociodemographic characteristics, care, prenatal, childbirth, birth, and newborn's hospitalization, as well as the baby's characteristics. Logistic regression analysis was carried out to assess the association between neonatal death and explanatory variables.

Results: the factors associated with death were from the countryside or other States $(O R=2.68 ; C I 95 \%=1.24-5.81)$, Apgar scores lower than 7 in the 1 st $(O R=9.52 ; C I 95 \%=$ 4.15-21.81) and the 5th $(O R=4.17 ; C 195 \%=1.53-11.34)$ minutes of life; and birth weight less than 999g $(O R=13.37$; $C 195 \%=3,64-49.04)$ and between 1,500 to 2,499g (OR=3.43; C195\%=1.37-8.58).

Conclusions: apgar and low birth weight were associated with the neonatal death among adolescent mothers, as well as the fact they come from the countryside and other States. These findings show, in addition to classic risks, potential difficulties for adolescents in having access to healthcare services in their hometown. To reduce the risks, there is a need for restructuring the maternal and child healthcare network and ensure a social protection network for these girls.
\end{abstract}

Key words Neonatal mortality, Teenage pregnancy, Adolescent, Pregnancy, Neonatal death

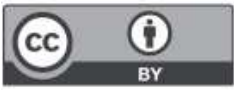




\section{Introduction}

Early motherhood is part of a broad and complex social context, involving the whole family, the teenage mothers, and their children. ${ }^{1}$ It occurs in high, middle and low income countries, although, it predominates in marginalized populations fostered by poverty. In the world, it is estimated that developing regions concentrate 21 million pregnant girls aged 15-19 and other 2 million younger ones. ${ }^{2}$ In Brazil, in $2015,18 \%$ of live births were of teenage mothers, and the Northeast region concentrates $32 \%$ within the country. 3

The understanding of adolescence as a phase of transition in life between childhood and adulthood is consensual as well as its close relationship with the sociocultural contexts of societies. 4,5 However, there is some disagreement concerning the age to start and end adolescence.4,5 The delimitation of this age group most considered internationally is between the ages of 10 and 19, although, there are propositions to extend it up to 24.5 The Ministry of Health adopts the age range of 10-19, even in disagreement with the Estatuto da criança e do adolescente (Brazilian Child and Adolescent Constitution) that defines between 12 and 18.4,5

The consequences of teenage girls' pregnancy, their families and the communities come up in different ways with negative social and economic effects, often perpetuating intergenerational cycles of poverty, poor schooling and health problems. ${ }^{2}$ Adolescents have differentiated emotional and social needs, and present increased risks of eclampsia, systemic infections, and pregnancy-induced anemia, among other factors contributing to maternal mortality. ${ }^{2}$

In addition, evidences show unfavorable results for their newborns related to perinatal morbidity and mortality, ${ }^{6,7}$ as they are at increased risk of low birth weight, premature birth, low Apgar scores, and severe neonatal conditions, with potential long-term repercussions and increased costs associated with these conditions for the healthcare system.2,6-8 Sociodemographic and obstetric conditions, as well as indication to admit to an intensive care unit, are also described as being associated with neonatal death. 9

In Brazil, neonatal mortality have reduced between 1990 to 2015, but it remains with high and discrepant numbers between Brazilian regions. 1 Despite the knowledge about the factors associated with neonatal death among adolescent mothers, inequalities between regions may exist and result from socioeconomic, healthcare or behavioral diffe- rences, which may vary according to the country and the location. ${ }^{10}$ The identification of factors associated with neonatal death in regions with a high teenage pregnancy rate may contribute to the improvement of specific interventions aimed to those who live in a situation of greater disadvantage and also to reduce regional disparities. This article aims to analyse the factors associated with neonatal death among adolescent mothers.

\section{Methods}

This is an analytical hospital-based cross-sectional study based on records of live birth statements (LBS), death certificates (DC) and medical records. The study was carried out in a tertiary institution linked to the Public Health System (SUS), the Instituto de Medicina Integral Prof. Fernando Figueira (IMIP), located in Recife, Pernambuco, in the Northeast region of Brazil. It assists an average of six thousand births per year, from which about $20 \%$ are adolescent mothers. It has 18 hospital beds in the Neonatal Intensive Care Unit, 32 in the Intermediate Care Unit, and 22 in the Kangaroo Neonatal Intermediate Care Unit.

This study included adolescent mothers between ages 10 and $19^{2}$ who had their births assisted at the institution between 2012 and 2016, selected from the Sistema de Informação sobre Nascidos Vivos (Sinasc) (Live Birth Information System) and all the neonatal deaths that occurred within less than 28 days of life, are collected from the Sistema de Informação sobre Mortalidade (SIM) (Mortality Information System). The adolescent mothers who were hospitalized and whose births did not occur during hospitalization, and those whose medical records were unavailable, were excluded. The 10 multiple pregnancy cases were included in the analysis without distinction. The data of all live births of adolescent mothers that occurred during the study period was identified through the annual reports at Sinasc and the data of all neonatal deaths was identified by SIM, all provided by the hospital epidemiology center. This was followed by a sampling procedure to select adolescents and subsequent collect information from the LBS, DC and medical records (Figure 1).

Adolescent mothers assisted during childbirth at the hospital and who were discharged but were readmitted to the same or another service, with an outcome of neonatal death, were excluded from the study, considering that the collection of information was done from the mother's medical records and the LBS. New admissions imply differentiated records 

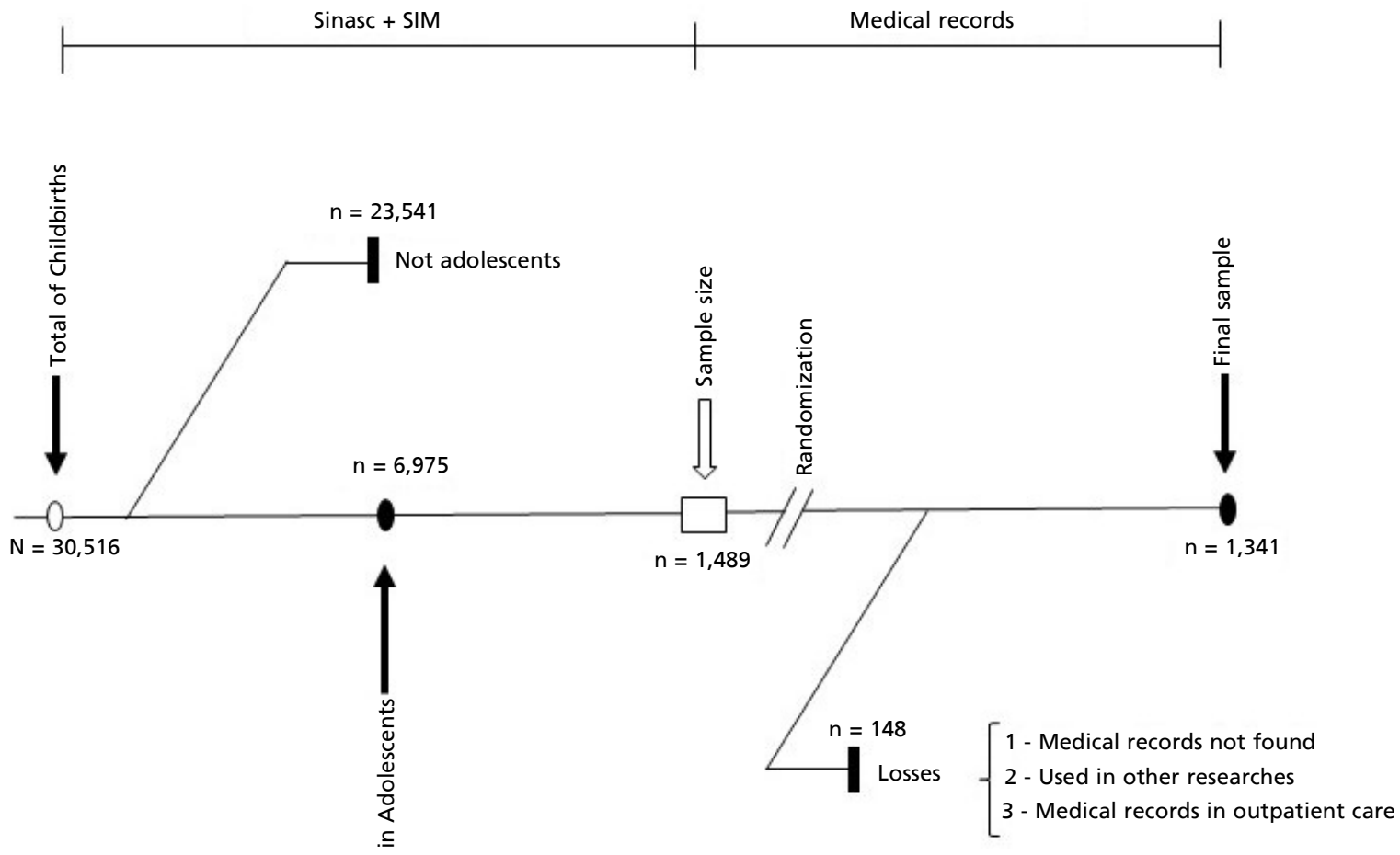

Sinasc = Sistema de Informação sobre Nascidos Vivos (Live Birth Information System); SIM = Sistema de Informação sobre Mortalidade (System of Information on Mortality); Medical Records= information in the Live Birth Statement (LBS) and healthcare medical records.

from those that occurred during the hospitalization for childbirth.

The dependent variable was the neonatal death among adolescent mothers', children who were born at the institution. The independent variables were divided into: 1. Sociodemographic and obstetric characteristics; 2. Characteristics of hospitalization; 3. Newborn's information.

a) sociodemographic and obstetric characteristics: maternal age (10-14, 15-19 years old); race/skin color (white, black, yellow, mixed , and indigenous); schooling according to the adequacy between the adolescent's age and years of schooling $(>8,<8)$; occupation (student, paying job , unpaid job , and dropout); marital status (with a partner, without a partner - it includes single, widow, or separated); city of origin (metropolitan region, countryside , or from other States); number of prenatal consultations $(>7,<7)$; trimester that started prenatal care (first, second, third); obstetric history (first pregnancy, recurrent pregnancy). 11

b) characteristics of hospitalization: access to healthcare service (spontaneous demand/selfreferral, hospital referral); adequacy of risk rating to waiting time according to the Ministry of Health 12 (adequate and inadequate); the risk rating determines the requirement of urgency for treatment, according to the potential risk factors, health grie-vances or level of suffering. It is color-coded and it estimated the waiting time, as follows: red, immediate assistance and major priority of emergency; orange, for priority I, very urgent, assistance within 10 minutes; yellow, for priority II, urgent, assistance within 30 minutes; green, for priority III, not very urgent, assistance within 120 minutes; blue, non-urgent, and assistance within 4 hours; reason for hospitalization (follow-up on natural birth, indication for cesarean section or clinical treatment that progressed to childbirth ); existence of previous isolated or associated morbidity (yes $=$ one or more maternal morbidities 
divided into: hypertensive, respiratory, anemia, heart disease, endocrine, arboviruses, urinary tract infection and other morbidities diagnosed during hospitalization; and no = no diagnosed morbidities); labor induction (yes, no); use of partograph (yes, no). The assessment of time and active phase was from the moment of hospitalization and identified on medical records; interval of maternal assessment in minutes, which was the maximum acceptable time between the mother's exam intervals $13(<60,>60)$; fetal assessment interval in minutes, which was the maximum acceptable time for fetal listening in the mother's belly13(<60, >60); type of childbirth (normal, cesarean); results of serology for AIDS, hepatitis B and syphilis during hospitalization (negative, positive); use of corticosteroids in case of prematurity (yes = all premature infants who used corticosteroids and had such indication; no = all the other); use of antibiotics before delivery (no; yes, prophylactic and in case of treatment). ${ }^{11}$

c) Newborn information: day of birth (Monday to Friday, on weekend), shift on duty at birth time (daytime, night time); gestational age in weeks $(<37$, 37-41.6, >42); sex (male, female); 1st minute Apgar score $(<7,7-10)$; 5 th minute Apgar score $(<7,7-10)$; birth weight in grams (up to $999,1000-1499,1500$ 2499, 2500 and + ).

The variables of maternal age, race/skin color, schooling, occupation, marital status, city of origin, number of prenatal consultations, trimester that started prenatal care, obstetric history, labor induction, type of childbirth, gestational age in weeks, sex, first-and fifth-minute Apgar scores, and birth weight. The other unavailable variables from Sinasc were collected from the medical records: access to healthcare service, adequacy of risk rating to waiting time, reason for hospitalization, existence of previous isolated or associated morbidity, result of serologies for AIDS, hepatitis B and syphilis at hospital admission, use of corticosteroids in case of prematurity, use of antibiotics before childbirth , use of partograph, maternal assessment interval in minutes, fetal assessment interval in minutes. For data collection, a model form was developed with objective questions concerning the variables in the Declaração de Nascido Vivo (Live Birth Statement) and added questions related to the assistance provided during hospitalization. The collection was carried out by four previously trained researchers.

The sampling was calculated through the OpenEpi program, considering the following parameters: (1) bilateral significance level (1-alpha) of $95 \%$; (2) power (1-beta, $\%$ detection probability) of $80 \%$; (3) prevalence of cases among unexposed ones of $4.5 \%$; and (4) ability to detect as significant, the Odds Ratio (OR) values equal to or higher than 1.9. In order to establish the estimated prevalence, it was determined as exposure condition of the adolescent. The estimated prevalence of cases among unexposed ones was established from the ratio of neonatal deaths in relation to the total number of childbirths performed in 2016. The OR value to be detected as significant was estimated from the mean established among several risk factors for neonatal death from the values reported in similar studies. 9

The estimated sampling size was 1,354 medical records. Considering possible losses, it was decided to inflate the sample by $10 \%$ resulting in 1,489 medical records. With the calculated sampling, the medical records were randomized by the WinPepi program (PEPI-for-Windows) according to a previously established number.

Data was processed using the Statistical Package for Social Sciences(SPSS), version 20.0. In order to assess the differences between the proportions of neonatal mortality and associated factors, the chisquare tests and chi-square withYates correction were used, when appropriate. All the conclusions followed the significance level of 5\%.

Odds ratios (OR) values for neonatal mortality were calculated for each exposed variable by logistic regression. After obtaining the gross Odds ratio values, the variables with a $p$-value $<0.20$ in the analysis were selected to make the multivariate regression model in order to assess the impact of explanatory variables. The results were expressed by the adjusted OR by corresponding $95 \%$ of the confidence intervals (CI95\%), with $p<0.05$ values being considered statistically significant. Possible confounding variables was tested.

This research was approved by thecommittee of ethics and research with human beings at the Universidade de Pernambuco (CAAE number:86934318.7.0000.5207 - Protocol = 2,710,076).

\section{Results}

30,516 births were assisted during the study period, of which $6,975(22.9 \%)$ were adolescents (between ages 10 and 19), and among these, 314 babies (4.5\%) died in the first 28 days of life. From the hospital census, 1,489 previously randomized medical records of adolescents were selected for analysis and the result was 1,341 , with a loss of approximately $10 \%$ due to the fact of not finding the files, or they were being used in researches, or because they were in face-to-face outpatient care (Figure 1). 
Of the 1,431 adolescent mothers who had their childbirths attended at the institution, the majority (1335) were between ages 15 and 19, and they had eight or more years of schooling (879), unpaid job, and they also were dropouts (845). The majority had come from cities in the metropolitan region (1144) and had less than 7 prenatal consultations (897). These last two variables were included in the multivariate regression model to show initially, a higher risk for neonatal mortality (Table 1).

Table 2 shows neonatal mortality according to the characteristics of hospitalization, in which the existence of previous isolated or associated morbidity and the use of the partograph showed to have a relation with the risk in the first analysis. The use of corticosteroids for pulmonary maturation did not show lower mortality when compared to those ones who did not use it (11.1 vs 9.1, $p=0.632$ - data not displayed on the table)

Variables related to newborn information, such as gestational age, birth weight, and the first-and fifth-minute Apgar scores, showed a greater possibility of being related to a higher risk of mortality (Table 3).

There was an association with neonatal mortalitywithin all the following variables: the place of origin, number of prenatal consultations, previous isolated or associated morbidity, use of partograph, gestational age, Apgar scores in the first and fifth minutes of life, and low birth weight. The variables that remained associated with neonatal mortality after logistic regression adjustment were the place of origin $(\mathrm{OR}=2.68 ; \mathrm{CI} 95 \%=1.24 ; 5.81)$, Apgar scores in the 1 st $(\mathrm{OR}=9.52 ; \mathrm{CI} 95 \%=4.15 ; 21.81)$ and 5 th

Table 1

\begin{tabular}{|c|c|c|c|c|c|}
\hline Indicators & $\mathbf{N}$ & $\mathbf{n}$ & $\%$ & $\mathrm{Cl} 95 \%$ & $p$ \\
\hline Maternal age (years) & & & & & 0.338 \\
\hline $10-14$ & 96 & 2 & 2.1 & $(0.25-7.7)$ & \\
\hline $15-19$ & 1,335 & 54 & 4.0 & $(3.0-5.3)$ & \\
\hline Race/Skin Color & & & & & 0.385 \\
\hline White & 243 & 7 & 2.9 & $(1.2-5.8)$ & \\
\hline Black & 134 & 5 & 3.7 & $(1.2-8.5)$ & \\
\hline Yellow & 8 & 1 & 12.5 & $(3.2-52.7)$ & \\
\hline Mixed & 997 & 39 & 3.9 & $(2.8-5.3)$ & \\
\hline Indigenous & 8 & 0 & 0.0 & - & \\
\hline Schooling in years & & & & & 0.317 \\
\hline$\geq 8$ & 879 & 30 & 3.4 & $(2.3-4.8)$ & \\
\hline$<8$ & 538 & 24 & 4.5 & $(2.9-6.6)$ & \\
\hline Occupation & & & & & 0.335 \\
\hline Student & 453 & 21 & 4.6 & $(2.9-7.0)$ & \\
\hline Paying job & 96 & 4 & 4.2 & $(1.1-10.3)$ & \\
\hline Unpaid job and dropout & 845 & 30 & 3.6 & $(2.4-5.0)$ & \\
\hline Marital status & & & & & 0.304 \\
\hline Living with a partner & 422 & 20 & 4.7 & $(2.9-7.2)$ & \\
\hline Without partner & 1,005 & 36 & 3.6 & $(2.5-4.9)$ & \\
\hline City of Origin & & & & & $<0.001$ \\
\hline Metropolitan region & 1,144 & 32 & 2.8 & $(1.9-3.9)$ & \\
\hline Countryside or from other States & 287 & 24 & 8.4 & $(5.4-12.2)$ & \\
\hline Number of prenatal consultations & & & & & 0.047 \\
\hline$\geq 7$ & 524 & 13 & 2.5 & $(1.3-4.2)$ & \\
\hline$>7$ & 897 & 41 & 4.6 & $(3.3-6.2)$ & \\
\hline \multicolumn{6}{|l|}{ Which trimester began prenatal care } \\
\hline First & 784 & 23 & 2.9 & $(1.9-4.4)$ & \\
\hline Second & 489 & 21 & 4.3 & $(2.7-6.5)$ & 0.100 \\
\hline Third & 68 & 4 & 5.9 & $(1.6-14.4)$ & \\
\hline Obstetric history & & & & & 0.919 \\
\hline First pregnancy & 1,062 & 42 & 4.0 & $(2.9-5.3)$ & \\
\hline Recurrent pregnancy & 365 & 14 & 3.8 & $(2.1-6.4)$ & \\
\hline
\end{tabular}

Values in bold indicate statistical difference, chi-square test. $\mathrm{Cl}=$ Confidence Interval. 
Table 2

\begin{tabular}{|c|c|c|c|c|c|}
\hline Indicators & $\mathbf{N}$ & $\mathbf{n}$ & $\%$ & $\mathrm{Cl} 95 \%$ & $p$ \\
\hline Access to healthcare service & & & & & 0.630 \\
\hline Spontaneous demand & 797 & 28 & 3.5 & $(2.3-5.0)$ & \\
\hline Referral & 599 & 24 & 4.0 & $(2.6-5.9)$ & \\
\hline Adequacy of risk rating to waiting time & & & & & 0.065 \\
\hline Adequate & 787 & 39 & 4.9 & $(3.5-6.7)$ & \\
\hline Inadequate & 588 & 17 & 2.8 & $(1.6-4.5)$ & \\
\hline Hospitalization reason & & & & & 0.777 \\
\hline Follow-up of natural birth & 1,363 & 52 & 3.8 & $(2.9-5.0)$ & \\
\hline Indication for cesarean section & 38 & 2 & 5.3 & $(0.6-17.8)$ & \\
\hline Clinical treatment that progressed to childbirth & 14 & 00 & 0.0 & - & \\
\hline Existence of previous isolated or & & & & & \\
\hline associated morbidity & & & & & 0.016 \\
\hline No & 704 & 35 & 5.0 & $(3.5-6.9)$ & \\
\hline Yes & 711 & 18 & 2.5 & $(1.5-4.0)$ & \\
\hline Results of serologies for AIDS, hepatitis B and & & & & & \\
\hline syphilis at hospitalization & & & & & 0.650 \\
\hline Negative & 1,348 & 53 & 3.9 & $(3.0-5.1)$ & \\
\hline Positive & 70 & 2 & 2.9 & $(0.4-9.9)$ & \\
\hline Use of corticosteroids in case of prematurity & & & & & 0.089 \\
\hline Yes & 101 & 7 & 6.9 & $(2.9-13.8)$ & \\
\hline No & 1,317 & 47 & 3.6 & $(2.6-4.7)$ & \\
\hline Use of antibiotics before childbirth & & & & & 0.890 \\
\hline No & 1,273 & 49 & 3.8 & $(2.9-5.1)$ & \\
\hline Yes, prophylactic and in case of treatment & 147 & 6 & 4.1 & $(1.5-8.7)$ & \\
\hline Labor Induction & & & & & 0.112 \\
\hline No & 1,081 & 47 & 4.3 & $(3.2-5.7)$ & \\
\hline Yes & 331 & 8 & 2.4 & $(1.1-4.7)$ & \\
\hline Use of partograph & & & & & 0.004 \\
\hline Yes & 423 & 7 & 1.7 & $(0.07-3.4)$ & \\
\hline No & 974 & 48 & 4.9 & $(3.7-6.5)$ & \\
\hline Maternal assessment interval in minutes & & & & & 0.056 \\
\hline$<60$ & 333 & 7 & 2.1 & $(0.9-4.3)$ & \\
\hline$>60$ & 1,089 & 48 & 4.4 & $(3.3-5.8)$ & \\
\hline Fetal assessment interval in minutes & & & & & 0.058 \\
\hline$<60$ & 332 & 7 & 2,1 & $(0.9-4.3)$ & \\
\hline$>60$ & 1,090 & 48 & 4.4 & $(3.3-5.8)$ & \\
\hline Type of childbirth & & & & & 0.829 \\
\hline Normal & 1,015 & 39 & 3.8 & $(2.8-5.2)$ & \\
\hline Cesarean section & 416 & 17 & 4.1 & $(2.4-6.5)$ & \\
\hline
\end{tabular}

Values in bold indicate statistical difference, chi-square test; AIDS= Acquired immunodeficiency syndrome, VDRL= test for syphilis.

minutes of life $(\mathrm{OR}=4.17$; CI95\% $=1.53 ; 11.34)$, and birth weight less than $999 \mathrm{~g}(\mathrm{OR}=13.37$; CI95\% $=$ $3.64 ; 49.04)$ and between 1.500 and $2.499 \mathrm{~g}$ $(\mathrm{OR}=3.43 ; \mathrm{CI} 95 \%=1.37 ; 8.58)$ (Table 4$)$.

\section{Discussion}

The results indicate that there is an association between neonatal death among adolescent mothers' newborns who had their childbirths assisted at the hospital studied, and the birth weight was less than 1,000g and between 1,500 and 2,499g, Apgar scores less than 7 in the first and fifth minute of life, and 


\section{Table 3}

\begin{tabular}{|c|c|c|c|c|c|}
\hline Indicators & $\mathbf{N}$ & $\mathbf{n}$ & $\%$ & $\mathrm{Cl} 95 \%$ & $p$ \\
\hline Day of birth & & & & & 0.599 \\
\hline Monday to Friday & 950 & 39 & 4.1 & $(3.0-5.6)$ & \\
\hline Weekend & 481 & 17 & 3.5 & $(2.1-5.6)$ & \\
\hline Shift on duty at birth time & & & & & 0.115 \\
\hline Daytime & 735 & 23 & 3.1 & $(2.0-4.7)$ & \\
\hline Night time & 695 & 33 & 4.7 & $(3.3-6.6)$ & \\
\hline Gestational age (weeks) & & & & & $<0.001$ \\
\hline $37-41.6$ & 1,022 & 19 & 1.9 & $(1.1-2.9)$ & \\
\hline$<37$ & 389 & 37 & 9.5 & $(6.8-12.9)$ & \\
\hline$\geq 42$ & 18 & 00 & 0.0 & - & \\
\hline Sex & & & & & 0.407 \\
\hline Female & 691 & 24 & 3.5 & $(2.2-5.2)$ & \\
\hline Male & 740 & 32 & 4.3 & $(3.0-6.6)$ & \\
\hline Apgar score / 1st minute & & & & & $<0.001$ \\
\hline $7-10$ & 1,224 & 15 & 1.2 & $(0.7-2.0)$ & \\
\hline$<7$ & 203 & 41 & 20.2 & $(15.00-26.4)$ & \\
\hline Apgar score $/ 5^{\text {th }}$ minute & & & & & $<0.001$ \\
\hline $7-10$ & 1,373 & 32 & 2.3 & $(1.6-3.3)$ & \\
\hline$<7$ & 55 & 24 & 43.6 & $(30.3-57.7)$ & \\
\hline Birth weight (g) & & & & & $<0.001$ \\
\hline $2,500-4,000$ & 1,063 & 15 & 1.4 & $(0.07-2.3)$ & \\
\hline $1,500-2,499$ & 265 & 19 & 7.1 & $(4.3-10.9)$ & \\
\hline $1,000-1,499$ & 31 & 5 & 16.1 & $(5.4-33.7)$ & \\
\hline Up to 999 & 16 & 17 & 94.1 & $(71.3-99.8)$ & \\
\hline
\end{tabular}

Values in bold indicate statistical difference, chi-square test.

Table 4

Not adjusted and adjusted gross risk estimated for neonatal mortality of adolescent mothers.

\begin{tabular}{|c|c|c|c|c|c|c|}
\hline \multirow[t]{2}{*}{ Variable } & \multicolumn{3}{|c|}{ Not adjusted } & \multicolumn{3}{|c|}{ Adjusted } \\
\hline & OR & $\mathrm{Cl} 195 \%$ & $p$ & OR & $\mathrm{Cl} 195 \%$ & $p$ \\
\hline City of origin & & & $<0.001$ & & & 0.012 \\
\hline Metropolitan region & 1 & & & 1 & & \\
\hline Countryside or from other States & 3.17 & $1.83-5.47$ & & 2.68 & $1.24-5.81$ & \\
\hline Number of prenatal consultations & & & & & & 0.902 \\
\hline$\geq 7$ & 1 & & & 1 & & \\
\hline$<7$ & 1.88 & $0.99-3.54$ & 0.047 & 0.94 & $0.36-2.40$ & \\
\hline \multicolumn{7}{|l|}{ Which trimester began prenatal care } \\
\hline First & 1 & & & 1 & & \\
\hline Second & 1.48 & $0.81-2.71$ & 0.199 & 2.05 & $0.91-4.61$ & 0.083 \\
\hline Third & 2.07 & $0.69-6.16$ & 0.192 & 2.42 & $0.53-10.91$ & 0.249 \\
\hline \multicolumn{4}{|c|}{ Adequacy of risk rating to waiting time } & & & 0.263 \\
\hline Adequate & 1 & & & 1 & & \\
\hline Inadequate & 0.58 & $0.32-1.04$ & 0.065 & 0.63 & $0.29-1.40$ & \\
\hline
\end{tabular}




\begin{tabular}{|c|c|c|c|c|c|c|}
\hline \multirow[t]{2}{*}{ Variable } & \multicolumn{3}{|c|}{ Not adjusted } & \multicolumn{3}{|c|}{ Adjusted } \\
\hline & OR & $\mathrm{Cl} 95 \%$ & $p$ & OR & $\mathrm{Cl} 95 \%$ & $p$ \\
\hline \multicolumn{7}{|l|}{ Existence of previous isolated or } \\
\hline associated morbidity & & & & & & 0.319 \\
\hline No & 1 & & & 1 & & \\
\hline Yes & 0.49 & $0.27-0.88$ & 0.016 & 0.67 & $0.31-1.45$ & \\
\hline Labor Induction & & & & & & 0.924 \\
\hline No & 1 & & & 1 & & \\
\hline Yes & 0.54 & $0.25-1.16$ & 0.112 & 0.95 & $0.36-2.51$ & \\
\hline Use of partograph & & & & & & 0.326 \\
\hline Yes & 1 & & & 1 & & \\
\hline No & 3.08 & $1.38-6.86$ & 0.004 & 2.48 & $0.40-15.26$ & \\
\hline Maternal assessment interval (min) & & & & & & 0.901 \\
\hline$\leq 60$ & 1 & & & 1 & & \\
\hline$>60$ & 2.14 & $0.96-4.79$ & 0.056 & 2.27 & $0.00-946856.34$ & \\
\hline Fetal assessment interval (min) & & & & & & 0.916 \\
\hline$\leq 60$ & 1 & & & 1 & & \\
\hline$>60$ & 2.13 & $0.95-4.77$ & 0.058 & 0.50 & $0.00-198803.39$ & \\
\hline Shift on duty at birth time & & & & & & 0.963 \\
\hline Daytime & 1 & & & 1 & & \\
\hline Night time & 1.54 & $0.89-2.65$ & 0.115 & 1.01 & $0.48-2.16$ & \\
\hline Gestational age (weeks) & & & & & & 0.196 \\
\hline $37-41.6$ & 1 & & & 1 & & \\
\hline$<37$ & 5.54 & $3.15-9.77$ & $<0.001$ & 1.75 & $0.74-4.08$ & \\
\hline Apgar score / 1st minute & & & & & & $<0.001$ \\
\hline $7-10$ & 1 & & & 1 & & \\
\hline$<7$ & 20.39 & $11.04-37.68$ & $<0.001$ & 9.52 & $4.15-21.81$ & \\
\hline Apgar score / $5^{\text {th }}$ minute & & & & & & 0.005 \\
\hline $7-10$ & 1 & & & 1 & & \\
\hline$<7$ & 32.44 & $17.14-61.39$ & $<0.001$ & 4.17 & $1.53-11.34$ & \\
\hline \multicolumn{7}{|l|}{ Birth weight (g) } \\
\hline $2,500-4,000$ & 1 & & & 1 & & \\
\hline $1,500-2,499$ & 4.92 & $2.46-9.81$ & $<0.001$ & 3.43 & $1.37-8.58$ & 0.008 \\
\hline $1,000-1,499$ & 11.07 & $3.78-32.39$ & $<0.001$ & 3.30 & $0.82-13.31$ & 0.093 \\
\hline Up to 999 & 72.95 & $31.12-171.03$ & $<0.001$ & 13.37 & $3.64-49.04$ & $<0.001$ \\
\hline
\end{tabular}

Values in bold indicate statistical difference, chi-square test; $\mathrm{OR}=$ odds ratio.

the fact of coming from the countryside or from other States.

Birth weight is one of the factors most frequently associated with neonatal mortality, similarly to the findings of this study.14-16 A systematic review and meta-analysis on complications associated with teenage pregnancy in sub-Saharan Africa conclude that young maternal age is associated with unfavorable outcomes with an increased risk of low or very low birth weight, maternal and perinatal mortality, and among others. 17 However, the authors admit limitations in the study due to the lack of adjustment for sociodemographic factors. Fall et al.,18 based on data from five cohort studies carried out in different countries in America, Africa and Asia, points out that mothers under 19 years old were associated with low-birth-weight newborns, premature and quite small for the gestational age, and it remained after the adjustments for socioeconomic status. 18,19

Gibbs et al.,20 in assessing the impact of age at first childbirth on mothers and children's health, through a systematic review, concluded that there is 
a biological effect of very young age, under 15 years old, in the first pregnancy with an increased risk of premature birth and low birth weight, factors that mediate several negative outcomes, including neonatal mortality. They also advocate studies in low-income countries should add to the chronological age information about the low gynecological age as a condition of exposure. 20

Apgar scores lower than 7 in the first and fifth minutes of life of the newborns were associated with neonatal death in conformity with the referential literature.13,14,20-26 The Apgar score is a predictor of morbidity and newborn mortality. A Brazilian research that investigated obstetric care in the country showed the association of low fifth-minute Apgar score with neonatal death,24 similar to hospital-based study 21 and a multi-center investigation, both carried out in the Northeast region of the country. 26 Additionally, there are reports that being born in a referral hospital for high-risk pregnancy, considering the difficulty to find a hospital bed in the Northeast region when compared to the South, results in higher risks of neonatal death. 7

The difficulties of women's access to healthcare services are multiple, and for girls between ages 10 and 19, there are even more difficulties. The results found in this study show the greatest risk for neonatal death among adolescent mothers from the countryside or from other States, with a significant number of those who arrive being referred from other healthcare unit services.2,27 The findings point out barriers for obtaining care compatible to their needs near their hometown. The greatest difficulty is to get a hospital bed in Brazil, it is a recurrently mentioned issue. 11

Restrictive policies for adolescents' access to sexual and reproductive healthcare services are described, including family planning and non-provision of contraceptives due to age, marital status, stigma associated with non-marital sexual behavior, or prejudice from healthcare professionals. These situations contribute to the discontinuity of assisting girls, even after overcoming initial obstacles.2,26

In this study, only $55 \%$ of the adolescents started prenatal care within the recommended time period, 13,25 and even $63 \%$ of them have not completed the consultation schedule yet. Adolescents may have the tendency not to seek early prenatal consultations due to the experience with unfriendly care services, either because their pregnancy is unwanted or hidden from their parents, or even lack of guidance, among other reasons; impeding prenatal interventions to prevent some adverse outcomes of teenage pregnancy. 27
Adolescent mothers are at higher risk of eclampsia, chorioamnionitis,puerperal endometritis and systemic infections than older women, and having complications at pregnancy and childbirth are the leading cause of death worldwide. ${ }^{27}$ In this study, previous maternal morbidity was not associated with neonatal death among adolescent mothers, perhaps due to prioritization of care and attention with greater grievance management. The data pointed out strangely in the bivariate analysis, the occurrence of neonatal deaths in women with a higher number of consultations ( $\mathrm{OR}=1.88, p=0.047)$, although, in the analysis adjusted for potential confounding factors, this variable is not identified as an associated factor, and the OR value was lower than 1 as expected, but without statistical significance $(\mathrm{OR}=0.94, p=0.902)$. The findings in the bivariate analysis are explained by the presence of a confounding factor adjusted in the multivariate analyses.

Intrapartum care may influence the risk of neonatal death. Some clinical conditions can increase the risk, such as the occurrence of fetal growth deviation. Adolescent pregnant women are at higher risk of fetal growth deviation, especially when it is lower than expected, requiring a differentiated intrapartum management as they often result in adverse perinatal outcomes. However, during the analysis of the medical records, it was detected absent, incomplete, or inadequate records, which together with the difficulty of accessing the newborns' records, it was quite difficult to assess thoroughly the care provided. Future studies should include and detail the assessment of intrapartum care provided to adolescent mothers.

Specific publications on neonatal mortality within this age group are not usual. Adolescent mothers are normally mentioned as part of the studied population. 11,23,28 This study differs in that because it focuses specifically on this population and, moreover, being hospital-based in a region with a high level of poverty, it shows characteristics that require particular attention from professionals and managers of the tertiary care units in order to minimize unfavorable outcomes. Another added consideration in this study was the likely difficulty of accessing referral services for adolescent mothers, and the referral of more severe cases of mothers from the countryside or from other States, with a consequent of increasing the risk of neonatal mortality.

The limits of this study are related to the use of data from Sinasc to identify adolescents who gave birth at the institution, and from SIM for neonatal deaths, due to the possibility of under-reporting, 
incompleteness and inconsistency of data. It can also occur with the data from the medical records. The problems were alleviated by the retrieval of information in the hospital epidemiology center, which performs an active search for events in the neonatal and maternity unit on a daily basis; and additionally, the collection from all sources in which the variables were available. The coverage of vital information in Pernambuco is known to be high 29 and the level of implementation of Sinasc and SIM is adequate. 30

It is concluded that neonatal death among adolescent mothers who were attended in aState referral hospital in the Northeast of Brazil was associated with birth weight less than $1,000 \mathrm{~g}$ and between 1,500 and 2,499g, low Apgar scores in the first and fifth minutes of life, and the fact of coming from a city outside the metropolitan region of Recife. The findings suggest the necessity of intersectoral State policies focused on adolescent mothers

\section{References}

1. Szwarcwald CL, Leal MC, Almeida WS, Barreto ML, Frias PG, Theme Filha MM, Domingues RMSM, Franca EB, Gama SGN, Boccolini CS, Victora C. Child Health in Latin America. Oxford Research Encyclopedia; 2019. 54p

2. WHO (World Health Organization). Adolescent pregnancy. Updated January 2018. Available from: http://www.who.int/mediacentre/factsheets/fs364/en/.

3. Azevedo AEBI, Eisenstein E, Bermudez BEBV, Fernandes EC, Oliveira HF, Hagel LD, Guimarães PR, Goldberg TBL, Fernandes EC, Bonetto DVS, Novadzki IM, Abreu JP, Santos KF, Rehme MFB, Bonassi R. Guia Prático de Atualização: Anticoncepção na Adolescência. Rio de Janeiro: Sociedade Brasileira de Pediatria, 2018 (Diretrizes)

4. Brasil. Lei 8.069, de 13 de Julho de 1990. Estatuto da Criança e do Adolescente. Brasília, DF: Ministério da Justiça; 1990.

5. Sawyer SM, Azzopardi PS, Wickremarathne D, Patton GC The age of adolescence. Lancet Child Adolesc Health. 2018; 2 (3): 223-8.

6. Azevedo WF, Diniz MB, Fonseca ESVB, Azevedo LMR, Evangelista CB. Complicações da gravidez na adolescência: revisão sistemática da literatura. Einstein. 2015; 13 (4): 618-26.

7. Gaiva MPM, Fujimori E, Sato APS. Fatores de risco maternos e infantis associados à mortalidade neonatal. Enferm. 2016; 25 (4): e2290015.

8. Oliveira EFV, Gama SGN, Silva CMFP. Gravidez na adolescência e outros fatores de risco para mortalidade fetal e infantil no Município do Rio de Janeiro, Brasil. Cad Saúde Pública. 2010; 26 (3): 567-78.

9. Bouzas ICS, Cader SA, Leão L. Gravidez na adolescência: uma revisão sistemática do impacto da idade materna nas complicações clínicas, obstétricas e neonatais na primeira and their families, as well as specific interventions to promote their health guidance, particularly concerning sexual and reproductive health. Population-based and hospital-based researches on this issue are still required to identify the most vulnerable groups and the healthcare obstacles faced by adolescent mothers regarding the definition of better alternatives to cope with the situation.

\section{Authors' contribution}

Araujo VMG, Silva JS, Bezerra Silva CL, Costa MSO: Research, Methodology, Writing, Revision and Editing; Costa EC, Frias PG, Barros MVG and Correia Junior MAV: Conceptualization, formal analysis, investigation, methodology, supervision, writing, original draft, writing, reviewing and editing. All authors approved the final version of the article. fase da adolescência. Adolesc Saúde. 2014; 11 (3): 7-21

10. Gibbsa CM, Wendtb A, Petersa S, Hoguea CJ. O impacto da primeira idade do primeiro parto na saúde materna e infantil. Paediatr Perinat Epidemiol. 2012; 26 (1): 259-84.

11. Lansky S, Friche AAL, Silva AAM, Campos D, Bittencourt SDA, Carvalho ML, Frias PG, Cavalcante RS, Cunha AJLA. Pesquisa nascer no Brasil : perfil da mortalidade neonatal e avaliação da assistência à gestante e ao recémnascido. Cad Saúde Pública. 2014; 30 (Supl.): 192-207.

12. Brasil. Ministério da Saúde. Secretaria de Atenção à Saúde. Departamento de Ações Programáticas Estratégicas. Manual de acolhimento e classificação de risco em obstetrícia. Brasília: Ministério da Saúde; 2017 [acesso 1 dez 2020]. Disponível em: http://bvsms.saude.gov.br/bvs/ publicacoes/manual_acolhimento_classificacao_risco_obst etricia.pdf.

13. Lansky S, França E, César C, Neto ML, Leal M. Mortes perinatais e avaliação da assistência ao parto em maternidades do Sistema Único de Saúde em Belo Horizonte, Minas Gerais, Brasil, 1999. Cad Saúde Pública. 2006; 22 (1): 117-30

14. Viellas EF, Gama SGN, Filha MMT, Leal MC. Gravidez recorrente na adolescência e os desfechos negativos no recém-nascido: um estudo no Município do Rio de Janeiro. Rev Bras Epidemiol. 2012; 15 (3): 443-54.

15. Santos NLAC, Costa MCO, Amaral MTR, Vieira GO, Bacelar EB, Almeida AHV. Gravidez na adolescência: análise de fatores de risco para baixo peso, prematuridade e cesariana. Ciênc Saúde Coletiva. 2014; 19 (3): 719-26.

16. Nascimento LFC. Fatores de risco para óbito em Unidade de Terapia Intensiva Neonatal. Rev Paul Pediatr. 2009; 27 (2): 186-92.

17. Grønvik T, Sandøy F. Complications associated with adolescente childbearing in Sub-Saharan Africa: A system- 
atic literature review and meta-analysis. PLoS ONE 2018, 13 (9): e0204327.

18. Fall CH, Sachdev HS, Osmond C, Restrepo-Mendez MC, Victora C, Martorell R, Stein AD, Sinha S, Tandon N, Adair L, Bas I, Norris S, Richter LM. Association between maternal age at childbirth and child and adult outcomes in the offspring: a prospective study in five low-income and middle-income countries (COHORTS collaboration). Lancet Global Health. 2015; 3 (7): e366-77.

19. Fall CH, Osmond C, Haazen DS, Sachdev HS, Victora C, Martorell R, Stein AD, Adair L, Norris S, Richter. Disadvantages of having na adolescent mother. Lancet Global Health. 2016; 4 (11): e787-8.

20. Gibbs CM, Wendt A, Peters S, Hogue CJ. The impact of early age at first childbirth on maternal and infant health. Paediatr Perinat Epidemiol. 2012; 26 (Suppl. 1): 259-84.

21. Stevens-Simon C, Beach RK, McGregor JA. Does incomplete growth and development predispose teenagers to preterm delivery? A template for research. J Perinatol. 2002; 22 (4): 315-23

22. Chen XK, Wen SW, Fleming N, Demissie K, Rhoads GG, Walker M. Teenage pregnancy and adverse birth outcomes: A large population based retrospective cohort study. Int J Epidemiol. 2007; 36 (2): 368-73.

23. Oliveira CM, Bonfim CV, Guimarães MJB, Frias PG Medeiros ZM. Mortalidade infantil : tendência temporal e contribuição da vigilância do óbito. Acta Paul Enferm. 2016; 29 (3): 282-90

24. Almeida AHV, Costa MCO, Gama SGN, Amaral MTR, Vieira GO. Baixo peso ao nascer em adolescentes e adultas jovens na Região Nordeste do Brasil TT - Low weight at birth in adolescent and young adult mothers in the Northeast Region of Brazil. Rev Bras Saúde Matern Infant. 2014; 14 (3): 279-86.
25. Aguiar JB. Fatores de risco para mortalidade neonatal, em hospital de referência. [dissertação]. Fortaleza: Universidade Estadual do Ceará; 2011. 84 p.

26. Silva CF, Leite AJM, Almeida NMGS, Leon ACMP, Olofin I. Factors associated with neonatal death in high-risk infants: a multicenter study in High-Risk Neonatal Units in Northeast Brazil. Cad Saúde Pública. 2014; 30 (2): 355-68.

27. Azevedo WF, Diniz MB, Fonseca ESVB, Azevedo LMR, Evangelista CB. Complicações da gravidez na adolescência: revisão sistemática da literatura. Einstein. 2015; 13 (4): 618-26

28. Almeida AHV. Resultados perinatais em mães adolescentes e adultas jovens na região Nordeste. [Dissertação]. Feira de Santana: Universidade Estadual de Feira de Santana; 2014 $65 \mathrm{p}$

29. Frias PG, Szwarcwald CL, Lira PIC. Avaliação dos sistemas de informações sobre nascidos vivos e óbitos no Brasil na década de 2000. Cad Saúde Pública. 2014; 30 (10): 2068 80.

30. Figueirôa BQ, Frias PG, Vanderlei LC, Vidal SA, Carvalho PI, Pereira CCB, Barreto IC, Maria LFBS, Lira PIC. Evaluation of the implantation of the Mortality Information System in Pernambuco state, Brazil, in 2012. Epidemiol Serv Saúde. 2019; 28 (1): 1-12.
Received on April 6, 2019

Final version presented on December 11, 2020

Approved on May 18, 2021 